\title{
Vacinas Contra o Papilomavirus Humano
}

\author{
Vaccines Against Human Papillomavirus
}

\author{
SIDNEY ROBERTO NADAL; CARMENRUTHMANZIONE
}

Médicos do Serviço de Coloproctologia do Hospital Emílio Ribas - SP - Brasil.

NADAL SR; MANZIONE CR. Vacinas Contra o Papiloma Virus Humano Rev bras Coloproct, 2006;26(3): 337-340.

RESUMO: Infecção pelo HPV é mais comum entre indivíduos jovens e sexualmente ativos e é tão prevalente que 75 a $80 \%$ da população será infectada durante sua vida. A maioria das lesões cede espontaneamente ao ponto de não ser detectada nem com os métodos mais sensíveis. Preocupam as infecções persistentes com os HPV oncogênicos, que aumentam o risco da neoplasia intraepitelial e do câncer. Duas formas de prevenção foram propostas: o rastreamento das lesões precursoras e a imunização contra o HPV, para evitá-las. Embora a incidência do câncer genital venha diminuindo devido aos métodos de rastreamento, seu custo é elevado e os resultados anormais provocam significantes distúrbios emocionais. Logo, a prevenção das doenças relacionadas ao vírus deveria ser disponível sob a forma de vacinação. Na década passada, iniciaram-se os testes clínicos com várias vacinas que tinham como alvo os tipos comuns do HPV. As vacinas profiláticas evitam a infecção pelo HPV e suas doenças associadas e as terapêuticas induzem a regressão das lesões pré-cancerosas e a remissão do câncer invasivo. As primeiras são compostas pela proteína capsídeo L1 do HPV que se auto-reproduz em partículas virus-like (VLP) quando expressa em sistemas recombinantes, induzindo forte resposta humoral com anticorpos neutralizadores. Determinam $100 \%$ de proteção contra a infecção pelos tipos específicos do HPV e impedem o aparecimento de neoplasias intraepiteliais de alto grau até pelo menos 5 anos após a imunização. A eficácia das vacinas feitas com as proteínas E6 e E7 também vem sendo pesquisada em modelos animais. As vacinas vêm mostrando maior efetividade quando administradas antes do início da atividade sexual e as campanhas de vacinação deverão ter como alvo as mulheres adolescentes e as pré-adolescentes. Espera-se, com o uso disseminado da vacina, que $70 \%$ dos cânceres cervicais sejam evitados, bem como a proporção das outras doenças anogenitais associadas à infecção pelo HPV.

Descritores: Infecções pelo Papilomavirus. Neoplasia intra-epitelial; prevenção e controle. Papilomavirus, vacina. Carcinoma de células escamosas.

O Papilomavirus humano (HPV) é um vírus de DNA de transmissão sexual que tem elevada prevalência em ambos os sexos ${ }^{1}$ e que causa verrugas e câncer anogenital. ${ }^{2}$ É mais comum entre indivíduos jovens e sexualmente ativos e é tão prevalente que 75 a $80 \%$ da população será infectada durante sua vida, ${ }^{3,4}$ sendo que metade dos novos casos acontece nos três primeiros anos de atividade sexual. ${ }^{5}$ Estimativas atuais sugerem que 20 milhões de norte-americanos estão infectados e mais que cinco milhões de infecções ocorrem cada ano. ${ }^{5}$ O HPV tem dois picos de prevalência: um mais elevado entre mulheres jovens, com queda gradual com a idade, e outro entre a quarta e quinta décadas. Esse segundo pico reflete a perda da imunidade original contra o vírus ao qual esteve exposta em idade mais jovem. A grande maioria das infecções cede espontaneamente ao ponto de não ser detectada nem com os métodos mais sensíveis. A preocupação é com as infecções persistentes determinadas pelos HPV oncogênicos, que aumentam o risco da neoplasia intraepitelial e do câncer. ${ }^{6}$

Foi relatado que o HPV é necessário para o desenvolvimento do câncer cervical. ${ }^{6}$ Os passos principais para a carcinogênese cervical incluem o epitélio de transição cervical, a presença de um ou mais dos 12 a 18 tipos oncogênicos, a persistência da infecção viral e a progressão clonal do epitélio com infecção persistente para pré-câncer e invasão. ${ }^{7}$ A importância dessa

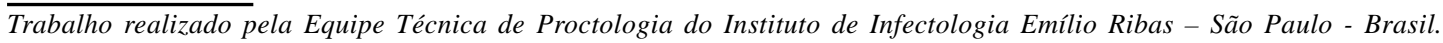

$\overline{\text { Recebido em 20/07/2006 }}$

Aceito para publicação em 01/08/2006 
zona de transição cervical foi estendida para outras áreas similares localizadas no canal anal e nas tonsilas, locais onde ocorre câncer. ${ }^{7}$ A história natural da doença mostrou que a citologia cervical sem displasia e a NIC 1, ou leve, têm comportamento similar, sendo que a maioria mostra regressão. Entretanto, a persistência da infecção pelo HPV pode provocar o desenvolvimento de NIC 3, a lesão precursora do câncer. Estima-se que o tempo de infecção até o surgimento da NIC 3 oscile entre um e 10 anos. Permanece incerto se lesões equivalentes diagnosticadas mais tarde têm história natural diferente. ${ }^{7}$

Esse fato nos leva a propor duas formas de prevenção: com rastreamento das lesões precursoras ou com imunização contra o HPV, para evitá-las. ${ }^{6}$ Os programas de rastreamento com citodiagnóstico, nos países mais desenvolvidos, reduziram em $75 \%$ a incidência do câncer cervical nos últimos 50 anos. ${ }^{6}$ Entretanto, a infecção só pode ser efetivamente evitada com abstinência sexual completa para todas as práticas sexuais, porque os preservativos não garantem proteção total e o HPV pode ser transmitido por atividades sexuais sem penetração. ${ }^{3}$ Embora a incidência do câncer genital venha diminuindo devido aos métodos de rastreamento, seu custo é elevado e os resultados anormais provocam significantes distúrbios emocionais. ${ }^{1}$ Logo, a prevenção das doenças relacionadas ao vírus deveria ser disponível sob a forma de vacinação. ${ }^{6}$

Mais que 100 genotipos já foram catalogados, sendo que 40 deles podem infectar a região anogenital. Entre esses últimos, os tipos 16, 18, 31, $33,35,39,45,51,52,56,58,59$ e 68 são considerados de alto risco, devido a sua associação com o câncer cervical e seus precursores, as neoplasias intraepiteliais cervicais (NIC). Outros tipos, como os $6,11,42,43,44$ e outros mais raros são tidos como de baixo risco ou não oncogênicos e usualmente provocam condilomas anogenitais. ${ }^{6}$ A maioria das doenças relacionadas é causada por quatro tipos: o HPV 6 e o 11 são responsáveis pelas lesões de baixo grau e $90 \%$ das verrugas anogenitais, ${ }^{4}$ e os tipos 16 e 18 provocam $70 \%$ das NIC de alto grau e o câncer cervical invasivo. ${ }^{4,8}$

O genoma do HPV 16 contém oito genes que codificam oito proteínas, sendo seis não estruturais e duas estruturais. Os genes estruturais L1 e L2 codificam as proteínas formadoras dos capsídeos maior e menor, respectivamente. ${ }^{9}$ Entre as não estruturais, a
E1 e a E2 estão relacionadas à replicação e transcrição do genoma viral; a E4 parece contribuir indiretamente para a replicação do genoma viral; as E5, E6 e E7 são designadas como oncoproteínas devido a capacidade de transformar células in vitro e, no caso das E6 e E7, induzir tumores in vivo. O E7 une-se com o produto do gene $\mathrm{Rb}$ causando proliferação celular incontrolada. A ligação do E6 com o produto da proteína do gene p53 degrada o primeiro, causando a perda da função de reparo do DNA, impedindo a apoptose ${ }^{6}$.

Na década passada, iniciaram-se os testes clínicos com várias vacinas que tinham como alvo os tipos comuns do HPV. ${ }^{10}$ Foram classificadas como profiláticas ou terapêuticas. ${ }^{10}$ As vacinas profiláticas evitam a infecção pelo HPV e as doenças a ela associadas e as terapêuticas induzem regressão das lesões pré-cancerosas e remissão do câncer invasivo. ${ }^{6,10}$ As vacinas profiláticas contra o HPV são compostas pela proteína capsídeo L1 do HPV que se autoreproduz em partículas virus-like (VLP) quando expressa em sistemas recombinates, ${ }^{11}$ induzem a forte resposta humoral com anticorpos neutralizadores. A eficácia das vacinas feitas com as proteínas E6 e E7 também vêm sendo pesquisadas em modelos animais. ${ }^{12,13}$ A injeção intramuscular da VLP resulta em resposta imune adaptativa eficaz para células $\mathrm{T}$ e $\mathrm{B}$, que são capazes de neutralizar as infecções naturais subseqüentes. ${ }^{11}$ A vacina HPV16 L1 VLP determinou alto índice de proteção contra a infecção persistente pelo HPV 16 e impediu o aparecimento das NIC 2 e 3 durante pelo menos 3,5 anos depois da imunização, ${ }^{14} \mathrm{e}$ a bivalente demonstrou mesma eficácia entre $4 \mathrm{e}$ 5 anos ${ }^{15}$.

A vacina bivalente, que protege contra os HPV 16 e 18 , e a quadrivalente, contra os tipos $6,11,16$ e 18 , têm mostrado redução significante da incidência de infecções persistentes pelo HPV. ${ }^{1}$ A vacina bivalente mostrou eficácia de $91,6 \%$ contra infecção incidental e $100 \%$ contra as persistentes pelos HPV 16/18. A vacina foi segura, bem tolerada e altamente imunogênica. ${ }^{3,6,9,16}$ Além disso, a análise dessa vacina contra infecção incidental por outros tipos oncogênicos indicou alto grau de proteção contra o HPV 45 e contra o HPV 31, o terceiro e o quarto tipos virais mais comumente associados ao câncer cervical. A vacina quadrivalente que protege contra os tipos oncogênicos e não oncogênicos mais comuns, também conferiu $100 \%$ de eficiência para prevenir doenças associadas 
aos tipos virais 16 e 18, sugerindo que a vacinação em massa diminuirá o ônus provocado pelas doenças associadas ao HPV. ${ }^{3}$

Doentes HIV-positivos bem como aqueles com outras causas de imunossupressão têm risco aumentado para câncer oral e anogenital associados ao HPV. A eficácia da vacina contra o HPV para reduzir a incidência desses tumores nos imunodeprimidos pode depender de vários fatores, incluindo os efeitos do imunocomprometimento na resposta à vacinação, se os doentes têm tipos virais não usados na vacina e se imunização deva ocorrer antes que a depressão imunológica seja acentuada. ${ }^{17}$

Embora as vacinas terapêuticas induzam imunidade celular e humoral, não demonstraram eficácia clínica consistente. ${ }^{10}$ De qualquer maneira parece sensato imaginar que a melhora das imunidades celular e humoral deva evitar a replicação viral nas células com DNA viral integrado, bem como impedir que novas infecções pelo HPV ocorram. De qualquer maneira, são necessárias novas opções. A proteína E2 de muitos tipos do HPV induz à parada do crescimento $\mathrm{e}$ à apoptose. O maior obstáculo ocorre na liberação dessa proteína nas células transformadas ou infectadas pelo HPV. Uma das possíveis soluções é associar a proteína E2 com a proteína VP22 do herpes simplex vírus que se mostraram capazes de induzir apoptose experimentalmente. ${ }^{18}$

Os temas que merecem discussão incluem se homens e mulheres deveriam ser vacinados; a durabilidade da resposta imune; a frequiência das doenças atribuíveis aos tipos do HPV utilizados na vacina e o acesso e o custo da vacina. Os modelos matemáticos de regressão para avaliar a eficácia da vacina contra o HPV demonstraram que a vacinação das mulheres pode ser custo-efetivo, o que não se comprovou quando a vacinação foi feita em homens e mulheres. ${ }^{19}$

As vacinas vêm se mostrando mais efetivas quando administradas antes do início da atividade sexual e as campanhas de vacinação deverão ter como alvo os adolescentes e os pré-adolescentes. ${ }^{1,16}$ Espera-se, com o uso disseminado da vacina, que $70 \%$ dos cânceres cervicais sejam evitados, bem como a mesma proporção das outras doenças anogenitais associadas à infecção pelo HPV. ${ }^{20}$ Devido à pouca idade do público-alvo para a vacinação, os médicos e os pais deverão auxiliar na tomada de decisão. ${ }^{21}$ De qualquer forma, a vacina contra o HPV é uma das esperanças para o futuro e a proposta do programa de vacinação, quando a mesma estiver disponível, deverá ser clara, concisa e com mensagem educativa tanto para o público leigo como para os profissionais de saúde. ${ }^{20}$

\footnotetext{
ABSTRACT: Papillomavirus infection is more common in young sexually active people. It is so prevalent that from $75 \%$ to $80 \%$ of this population will be infected in their lifetime. Most lesions will be eradicated spontaneously at the point of not being detected even with the most sensible methods. Persistent infections with oncogenic HPV increase intraepithelial neoplasia and cancer risks. Two ways of prevention may be proposed: screening for precursor lesions and immunization against HPV, to avoid them. Although anogenital cancer incidence is decreasing with screening methods, costs are high and emotional disturbance may be caused by an abnormal result. So, vaccines to prevent diseases associated to HPV must be available. In the last decade, clinical tests began with several vaccines targeting the most frequent HPV types. The goal of prophylactic vaccines is to prevent primary or persistent HPV infections, and thus prevent cervical cancer and/or genital warts and the aim of the therapeutic types is to prevent progression of HPV infection, induce regression of intraepithelial neoplasia or condylomata, or eradicate residual cervical cancer. Prophylactic HPV vaccines in late stages of clinical testing are composed of HPV L1 capsid protein that self-assemble into virus-like particles (VLPs) when expressed in recombinant systems, resulting in strong adaptive immune responses that are capable of neutralizing subsequent natural infections. Some studies observed $100 \%$ efficacy in preventing clinical disease for specific HPV types at least 5 years after immunization. Vaccines that target E6 and E7 proteins also represent an important strategy to control HPV-associated lesions and are in test in animal models. HPV vaccines seem to be more effective when administered prior to initiation of sexual activity, and vaccination campaigns should target preadolescent and adolescent populations. It is expected that with good coverage of the vaccine, $70 \%$ of cervical cancers will be prevented like other anogenital diseases caused by HPV infection.
}

Key words: Papillomavirus infections. Intra-epithelial neoplasia; prevention and control. Papillomavirus, vaccine. Carcinoma, squamous cell. 


\section{REFERÊNCIAS}

1. Soper D. Reducing the Health Burden of HPV Infection Through Vaccination. Infect Dis Obstet Gynecol. 2006;14(1):83084.

2. Genther SM, Sterling S, Duensing S, Münger K, Sattler C, Lambert PF. Quantitative role of the human Papillomavirus type $16 \mathrm{E} 5$ gene during the productive stage of the viral life cycle. J Virol 2003;77(5):2832-42.

3. Weaver BA.Epidemiology and natural history of genital human papillomavirus infection. J Am Osteopath Assoc. 2006;106(3 Suppl 1):S2-8.

4. Wiley D, Masongsong E. Human papillomavirus: the burden of infection. Obstet Gynecol Surv. 2006 ;61(6 Suppl 1):S314.

5. Cox JT. The development of cervical cancer and its precursors: what is the role of human papillomavirus infection? Curr Opin Obstet Gynecol. 2006;18 Suppl 1:s5-s13.

6. Franco EL, Harper DM. Vaccination against human papillomavirus infection: a new paradigm in cervical control. Vaccine 2005;23:2388-94.

7. Moscicki AB, Schiffman M, Kjaer S, Villa LL. Chapter 5: Updating the natural history of HPV and anogenital cancer. Vaccine. 2006;24 Suppl 3:S42-51.

8. Ferris DG. Vaccines for preventing HPV-related anogenital infection and neoplasia. J Am Osteopath Assoc. 2006;106(3 Suppl 1):S9-13.

9. Harper DM, Franco EL, Wheeler C, Ferris DG, Jenkins D, Schuind A et al. Efficacy of a bivalent L1 virus-like particle vaccine in prevention of infection with human papillomavirus types 16 and 18 in young women: a randomised controlled trial. Lancet. 2004;364(9447):1757-65.

10. Kahn JA, Bernstein DI. Human papillomavirus vaccines and adolescents. Curr Opin Obstet Gynecol. 2005;17(5):476-82.

11. Villa LL. Prophylactic HPV vaccines: reducing the burden of HPV-related diseases. Vaccine. 2006;24 Suppl 1:S23-8.

12. Samorski R, Gissmann L, Osen W. Codon optimized expression of HPV 16 E6 renders target cells susceptible to E6-specific CTL recognition. Immunol Lett. 2006;107(1): 41-9.
13. Lin CT, Tsai YC, He L, Calizo R, Chou HH, Chang TC et al. A DNA vaccine encoding a codon-optimized human papillomavirus type 16 E6 gene enhances CTL response and anti-tumor activity. J Biomed Sci. 2006;13(4):481-8.

14. Mao C, Koutsky LA, Ault KA, Wheeler CM, Brown DR, Wiley DJ et al. Efficacy of human papillomavirus-16 vaccine to prevent cervical intraepithelial neoplasia: a randomized controlled trial. Obstet Gynecol. 2006;107(1):18-27.

15. Harper DM, Franco EL, Wheeler CM, Moscicki AB, Romanowski B, Roteli-Martins CM et al. Sustained efficacy upt to $4-5$ years of a bivalent L1 virus-like particle vaccine against human papillomavirus types 16 and 18: follow-up from a randomised control trial. Lancet. 2006;367: 1247-55.

16. Ault KA. Vaccines for the prevention of human papillomavirus and associated gynecologic diseases: a review. Obstet Gynecol Surv. 2006;61(6 Suppl 1):S26-31.

17. Palefsky JM, Gillison ML, Strickler HD. Chapter 16: HPV vaccines in immunocompromised women and men. Vaccine. 2006;24 Suppl 3:S140-6.

18. Green KL, Gaston K. Development of a topical protein therapeutic for human papillomavirus and associated cancers. BioDrugs. 2006;20(4):209-18.

19. Dasbach EJ, Elbasha EH, Insinga RP. Mathematical models for predicting the epidemiologic and economic impact of vaccination against human papillomavirus infection and disease. Epidemiol Rev. 2006;28:88-100.

20. Garland SM.Human papillomavirus vaccines: challenges to implementation. Sex Health. 2006 ;3(2):63-5.

21. Gonik B. Strategies for Fostering HPV Vaccine Acceptance. Infect Dis Obstet Gynecol. 2006 ;14(1):36797.

\section{Endereço para correspondência:} SIDNEY ROBERTO NADAL

Rua Dr. Virgilio de Carvalho Pinto, 381 - Apto. 23

05415-030 - São Paulo (SP) - Brasil

Tel./Fax (+55 11) 3337-4282

E-mail:srnadal@terra.com.br 